\title{
ОБЗОР БИОСОВМЕСТИМЫХ ФОТОПОЛИМЕРНЫХ СМОЛ ДЛЯ СЬЕМНОГО ПРОТЕЗИРОВАНИЯ
}

\section{BIOCOMPATIBLE PHOTOPOLYMER RESINS FOR REMOVABLE PROSTHETICS}

Summary. Dentistry is one of the most developing specialties in the field of $3 D$ printing, and it is in orthopedic dentistry that not only the speed and accuracy of the manufactured orthopedic structures are most important, but also the properties of the materials used: safety; biocompatibility; compliance with medical. Despite the development of modern dentistry and the emergence of new basic materials for the manufacture of removable dentures, today, $98 \%$ of all removable plate dentures in the world are made of acrylate-based plastics. The article presents the results of a review of biocompatible photopolymer resins for the manufacture of removable dentures. The composition and characteristics of photopolymer resins and the stages of the polymerization process are described; a classification of biocompatible resins is presented. Analysis of the assortment of the Russian market of biocompatible photopolymer resins used in orthopedic dentistry for removable prosthetics showed that the main market share is occupied by only three companies producing these resins. The presented review of biocompatible photopolymer resins for removable prosthetics showed that today an active search continues in the field of developing modern base materials for the manufacture of complete removable plate prostheses with optimal characteristics.

Keywords: removable prosthesis, biocompatible photopolymer resin, 3D printing, SLA, stereolithography.
Эртесян Альберт Робертович

К.м.н., ассистент, ФГБОУ ВО «Самарский государственный медицинский университет» Минздрава России, Самара albertertesyan@gmail.com

Садыков Мукатдес Ибрагимович Д.м.н., професссор, ФГБОУВО «Самарский государственный медицинский университет» Минздрава России, Самара

Сараев Александр Рудольфович

К.м.н., доцент, ФГБОУ ВО «Самарский государственный медицинский университет» Минздрава России, Самара

Нестеров Александр Михайлович Д.м.н., профессор, ФГБОУ ВО «Самарский государственный медицинский университет» Минздрава России, Самара

Аннотация. Стоматология - является одной из наиболее развивающейся специальностью в области 3D-печати, и именно в ортопедической стоматологии наиболее важны не только скорость и точность изготовленных ортопедических конструкций, но и свойства используемых материалов: безопасность; биосовместимость; соответствие медицинским. Несмотря на развитие современной стоматологии и появлением новых базисных материалов для изготовления съемных протезов, на сегодняшний день, 98\% всех съемных пластиночных протезов в мире изготавливаются из пластмасс на основе акрилатов. В статье представлены результаты обзора биосовместимых фотополимерных смол для изготовления съемных протезов. Описан состав и характеристики фотополимерных смол, и этапы процесса полимеризации, представлена классификация биосовместимых смол. Анализ ассортимента российского рынка биосовместимых фотополимерных смол, используемых в ортопедической стоматологии для съемного протезирования показал, что основную долю рынка занимают лишь три компании производящие данные смолы. Представленный обзор биосовместимых фотополимерных смол для съемного протезирования, показал, что на сегодняшний день продолжается активный поиск в области разработки современных базисных материалов для изготовления полных съемных пластиночных протезов с оптимальными характеристиками.

Ключевые слова: съемный протез, биосовместимая фотополимерная смола, 3D-печать, SLA, стереолитография. 
A нализ научной литературы показывает, увеличение количества пациентов, нуждающихся больных в съемном протезировании, в связи с чем врачам стоматологам-ортопедам приходиться задумываться о решении существующей на сегодняшний день проблемы ортопедического лечения таких пациентов $[2,4]$. Важнейшей задачей современной ортопедической стоматологии является восстановление утраченных функций зубочелюстной системы при нарушении целостности зубных рядов.

В современной ортопедической стоматологии поиск новых методов, современных материалов и усовершенствование имеющихся, является первостепенной задачей в развитии современной стоматологии. Основным материалом для изготовления полных съемных пластиночных протезов является базисная пластмасса. Базисный материал, используемый в ортопедической стоматологии, находящийся непосредственно в контакте с тканями протезного ложа и биологической жидкостью, он должен обладать медико-техническими свойствами: не раздражать слизистую оболочку полости рта; обладать достаточной прочностью; прочно соединяться с искусственными зубами; не деформироваться; не изменять объема в процессе пользования протезом; хорошо шлифоваться и полироваться; соответствовать цвету слизистой оболочки полости рта. На сегодняшний день существует достаточное большое количество базисных материалов используемых при изготовлении съемных зубных протезов, но не все они широко применяются в зуботехнической лаборатории.

Несмотря на развитие современной стоматологии и появлением новых базисных материалов для изготовления съемных протезов, на сегодняшний день, 98\% всех съемных пластиночных протезов в мире изготавливаются из пластмасс на основе акрилатов [3].

Стоматология - является одной из наиболее развивающейся специальностью в области 3D-печати, и именно в ортопедической стоматологии наиболее важны не только скорость и точность изготовленных ортопедических конструкций, но и свойства используемых материалов: безопасность; биосовместимость; соответствие медицинским параметрам [1].

SLA 3D-принтеры - это оборудование, при помощи которого посредством стереолитографического метода возможно создавать ортопедические конструкции, в том числе съемные пластиночные протезы. Фотополимерные смолы состоят из двух групп, основных и боковых; комбинаций длинных и коротких мономеров; олигомеров; фотоинициаторов; добавок [6]. Это обеспечивает уникальные возможности по созданию различных формул с большим количеством оптических, механических и термических свойств - от прозрачных до окрашенных пластиков, от гибких до жестких, от вязких до термостойких [7].

Цепочки мономеров и олигомеров в полимере имеют на концах активные молекулярные группы. При попадании УФ-излучения на полимер, молекула фотоинициатора распадается на две части, а соединявшая их связь образует два очень реактивных радикала. Эти молекулы передают реактивные радикалы активным группам цепочек мономеров и олигомеров, которые в свою очередь реагируют с другими активными группами, образуя более длинные цепочки [8]. По мере удлинения цепочек и возникновения перекрестных связей пластик начинает затвердевать. Весь процесс перехода от жидкого до высокополимеризованного твердого состояния протекает за миллисекунды.

В процессе стериолитографического метода 3D-печати компоненты полимера образуют ковалентные связи, что обеспечивает высокую боковую прочность, но реакция полимеризации не доводится до завершения. Процесс 3D-печати модулируется таким образом, что слой поддерживается в полупрореагировавшем состоянии, которое называет «зеленым». Зеленое состояние отличается от полностью застывшего в одном важном моменте: на поверхности всё еще остаются полимеризируемые группы, которые образуют ковалентные связи с последующим слоем. Когда последующий слой отвердевает, в реакцию полимеризации вовлекаются группы предыдущего слоя, образуя не только боковые ковалентные связи, но и связи с предыдущим слоем. Это означает, что на молекулярном уровне в плане химических связей разницы по пространственным осям X, Y и Z нет, напечатанный объект по технологии SLA, является непрерывной полимерной сетью. Непрерывный объект, напечатанный по технологии SLA, изотропен [9].

Изотропность имеет как механические, так и оптические преимущества. Изотропные детали идеальны для стоматологии, поскольку отражают ряд свойств традиционных базисных полимеров, не страдают от расслоения и пористости. Образование химических связей и отсутствие видимых слоев внутри объекта позволяют печатать оптически чистые детали.

После завершения процесса стереолитографии, напечатанная деталь остается на рабочей платформе в вышеупомянутом «зеленом» состоянии. Хотя она имеет конечную форму и вид, реакция полимеризации не доведена до конца, механические и термические свойства сформированы не до конца.

Дополнительное УФ отверждение завершает процесс полимеризации и стабилизирует механические 
свойства, что позволяет достичь максимально возможной прочности конструкции и стать более стабильной, что особенно важно в случае функциональных пластиков для стоматологии.

Стоматологические и медицинские SLA-смолы делятся на 2 класса биосовместимости $[8,9]$.

Фотополимерная смола для медицинских приборов - Custom Medical Appliances (биосовместимость I класса). Биосовместимые смолы класса I могут предназначены для изготовления медицинского оборудования. Конструкции, напечатанные на этой смоле, можно стерилизовать автоклаве для непосредственного использования в операционной.

Правила биосовместимости класса I касаются материалов, которые разрешено использовать для: не инвазивных устройств, которые контактируют с неповрежденной кожей; приспособления для временного применения или кратковременного использования в ротовой полости; многоразовые хирургические инструменты.

Стоматологическая долгосрочная биосовместимая смола - Dental Long Term (биосовместимость lla класса). Эти смолы специально разработаны для долгосрочных стоматологических конструкций. Биосовместимые смолы класса ІІа могут контактировать с организмом человека. Высокая устойчивость к разрушению и износу делают данную смолу идеальным вариантом для изготовления ортопедических конструкций.

Правила биосовместимости класса Ila касаются материалов, которые разрешено использовать для: устройств, вступающих в контакт с биологическими жидкостями; устройств, используемых для введения вещества в организм человека или удаления вещества и из него; инвазивных краткосрочных устройств; ортопедические конструкции.

На сегодняшний день, на отечественном рынке фотополимерные смолы для печати съемных ортопедических конструкций представлены несколькими компаниями. Все они сертифицированы на территории ЕАЭС и имеют регистрационные удостоверения.

Нидерландская компания NextDent B.V., выделенной в 2012 году из состава Vertex-Dental B.V., ранее занимавшаяся стоматологическими материалами.

NextDent Denture 3D+ - это мономер на основе акриловых эфиров, используемый для печати на всех лазерных и DLP-принтерах, используется при построении базисов съемных протезов. Благодаря тому, что остаток мономера в полученном полимере после процесса полимеризации минимален, продукт является биосовместимым, он имеет сертификацию ІІа класса и предназначен для постоянного использования в полости рта. Характеризуется низкими показателями усадки $( \pm 1,4 \%)$ по сравнению с общепринятыми РММА материалами, используемыми для изготовления съемных протезов.

NextDent C\&B MFH (Micro Filled Hybrid) - биосовместимый фотополимерный расходный материал IIa класса, используется при построении искусственных зубов для съемных протезов. Обладает прочностью и износостойкостью, конечные продукты поддаются различным видам постобработки, включая полировку.

Следующий представитель - Denture Base Resin и Denture Teeth Resin, от американской компании Formlabs. Компания основана в 2011 году в Массачусетском техническом университете.

Denture Base Resin - долговечный биосовместимый полимер Ila класса, используется для печати на SLA-принтерах, предназначен для изготовления базисов съемных протезов, поддерживает разрешение печати в 50 мкм. Усадку данного материала не стоит рассматривать, так как она составляет всего 0,05\%. Выпускается в цветах LP (Light Pink), OP (Original Pink), RP (Reddish Pink), DP (Dark Pink).

Denture Teeth Resin - биосовместимый полимер Ila класса предназначен для изготовления искусственных зубов для съемных протезов, временных искусственных коронок. Выпускается в цветах A1, A2, A3, A3.5, B1, B2 соответствующих шкале Vita.

Смолы Denture Base Resin и Denture Teeth Resin: не мутагенны; не цитотоксичны; не вызывают покраснений слизистой или отека; не вызывают системную токсичность. Оба материала соответствуют стандартам ISO: ISO 207951:2013 (Стоматология. Основные полимеры. Часть 1. Основные полимеры для зубных протезов); ISO 22112:2017 (Стоматология. Искусственные зубы для зубных протезов).

Проведя обзор биосовместимых фотополимерных смол для изготовления полных съемных пластиночных протезов, можно сделать вывод о том, что на сегодняшний день продолжается активный поиск и разработка новых базисных материалов для изготовления съемных пластиночных протезов с оптимальными характеристиками. Важной задачей дальнейшего изучения является исследование биосовместимых фотополимерных смол, сравнительный анализ их свойств, экономическую эффективность с известными базисными пластмассами в ортопедической стоматологии. 


\section{ЛИТЕРАТУРА}

1. Малаев, И.А., Пивовар, М. Л. Аддитивные технологии: применение в медицине и фармации // Вестник фармации. — 2019.—№ . 2.—C. 98-107.

2. Садыков М.И., Трунин Д. А., Нестеров А. М., Чистякова М. С. Иммунологический и микробиологический статус полости рта у пациентов пожилого возраста при использовании съемных пластиночных протезов. Наука и инновации в медицине. - 2016. — № . 2. - C. 50-54.

3. Штана, В.С., Рыжова, И. П. Обзор современных базисных полимеров в ортопедической стоматологии / В. С. Штана, И. П. Рыжова // Научные ведомости Белгородского государственного университета. Серия: Медицина. Фармация. 2019.— № . 42 (2). — C. 224-234. D0I: 10.18413/2075-4728-2019-42-2224-234

4. Braian, M., Jimbo, R., Wennerberg, A. Production tolerance of additive manufactured polymeric objects for clinical applications / M. Braian, R. Jimbo, A. Wennerberg // Dent Mater. - 2016. - Vol. 32. - P. 853-861.

5. Can 3D Printed Dentures Look Good?, URL: https://3d.formlabs.com/recording-can-3d-printed-dentureslookgood?alild=eyJpljoibjA3cmdDY1wvcFg100IFZ30iLCJ0I joickhc L2FZYOInKOhZMnF5UFBRV1p3MGc9PSJ9 (date of the application 15.06.2020).

6. SLA 3D-printing, URL: https://3dpt.ru/blogs/support/sla (date of the application 15.06.2020).

7. Revilla-León, M., Özcan, M. Additive manufacturing technologies used for processing polymers: current status and potential application in prosthetic dentistry / M. Revilla-León, M. Özcan // Prosthodont. — 2019. — Vol. 28. - P. 146-158.

8. Revilla-León, M., Olea-Vielba, M., Esteso-Saiz, A. Marginal and internal gap of handmade, milled and 3D printed additive manufactured patterns for pressed lithium disilicate onlay restorations / M. Revilla-León, M. Olea-Vielba, A. Esteso-Saiz // Eur. J. Prosthodont Restor Dent. — 2018. — Vol. 26.—P. 31-38.

9. Tahayeri, A., Morgan, M., Fugolin, A. P., 3D printed versus conventionally cured provisional crown and bridge dental materials / A. Tahayeri, M. Morgan, A. P. Fugolin // Dent Mater. - 2018. — Vol. 34. - P. 192-200.

( ) Эртесян Альберт Робертович ( albertertesyan@gmail.com ), Садыков Мукатдес Ибрагимович,

Сараев Александр Рудольфович, Нестеров Александр Михайлович.

Журнал «Современная наука: актуальные проблемы теории и практики»

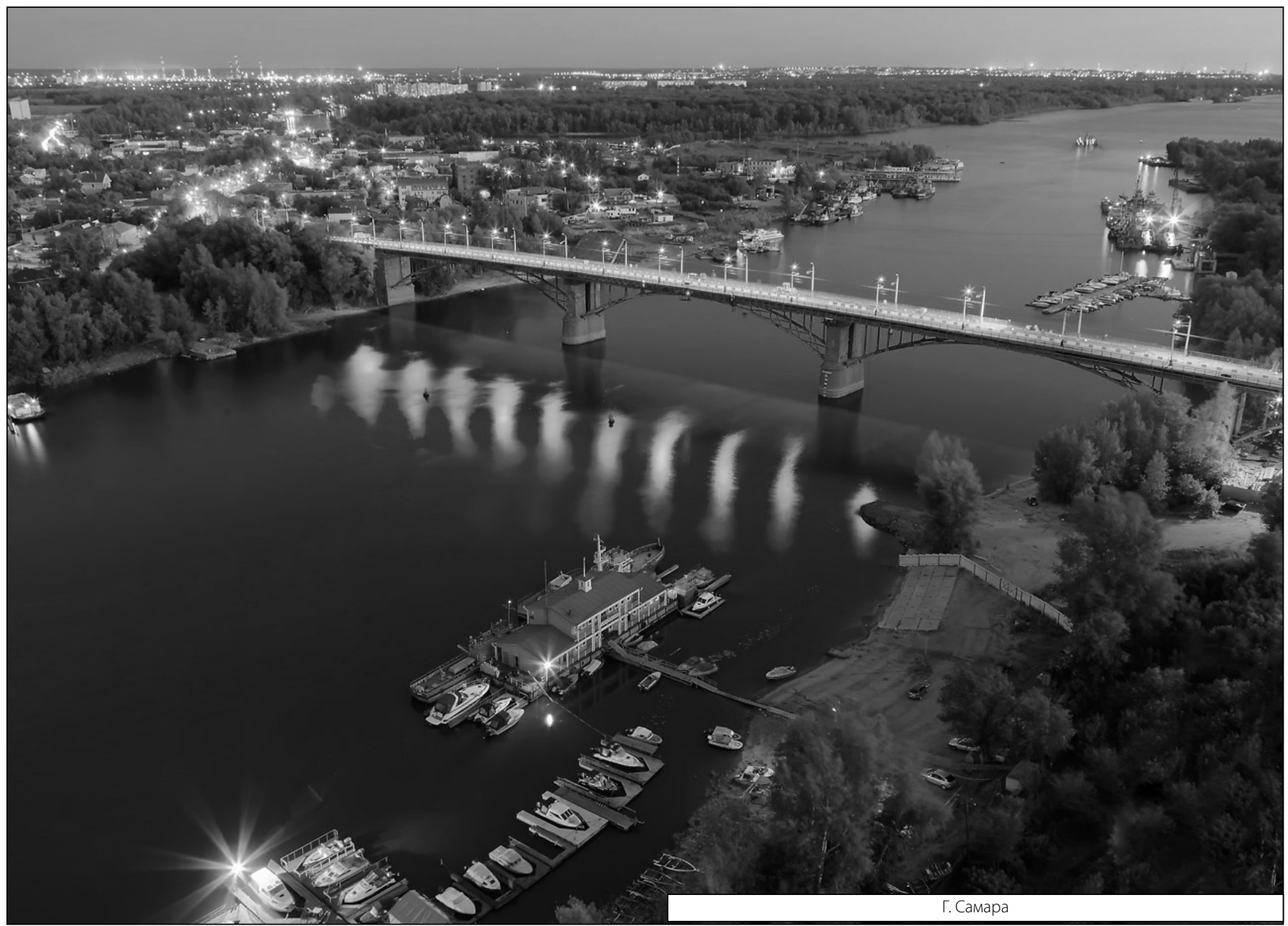

